\section{ARTIGOS}

\author{
Sarita Albagli
}

\begin{abstract}
Resumo
Discute-se a emergência recente da problemática da biodiversidade, de modo associado com a passagem de um paradigma tecno-econômico intensivo em energia fóssil e recursos naturais para um outro baseado em informação e no uso crescente de ciência e tecnologia no processo produtivo. Nesse contexto, é por intermédio das biotecnologias avançadas que se busca agregar valor à biodiversidade no mercado globalizado, valorizando-se não os organismos vivos em si, mas a informação genética neles contidas.
\end{abstract}

Palavras-chave

Biodiversidade; Informação; Ciência; Tecnologia; Biotecnologia.

\title{
Da biodiversidade à biotecnologia: a nova fronteira da informação*
}

\section{INTRODUÇÃO}

A informação ocupa um lugar cada vez mais proeminente nas sociedades contemporâneas. A emergência de uma sociedade da informação associa-se a um espectro amplo e diverso de transformações, dentre as quais se destacam aquelas que caracterizam a configuração de um novo paradigma técnico-econômico, baseado no desenvolvimento de um conjunto de tecnologias genéricas e na adoção de novos formatos organizacionais.

As chamadas novas tecnologias compreendem um conjunto de aplicações de descobertas científicas, cujo núcleo central consiste no desenvolvimento de uma capacidade cada vez maior de tratamento da informação, bem como de sua aplicação direta no processo produtivo: seja de informação simbólica, por meio da comunicação inteligente entre máquinas ou por máquinas, como na microeletrônica e na informática; seja ainda da informação da matéria viva, por intermédio da engenharia genética, base das biotecnologias avançadas.

\footnotetext{
* Artigo elaborado a partir da tese de doutorado Dimensão Geopolítica da Biodiversidade, desenvolvida com o apoio financeiro do WWF Fundo Mundial para a Natureza - e aprovada sem novembro de 1997, no Programa de PósGraduação em Geografia da UFRJ. Um resumo do mesmo foi apresentado durante o III Enacib, realizado em setembro de 1997, no Rio de Janeiro.
}

No caso das biotecnologias, a diversidade biológica e genética é matéria-prima básica para os avanços que se observam nessa área, sendo transformada de mero recurso natural em recurso informacional. Verifica-se, por outro lado, desigual distribuição espacial de recursos biogenéticos e de recursos científico-tecnológicos. Enquanto a biodiversidade encontra-se majoritariamente situada em países em desenvolvimento (localizados nos trópicos, ao Sul), os conhecimentos que fundamentam as modernas biotecnologias estão amplamente concentrados em países de economia avançada (do Norte).

O controle de informações estratégicas, bem como das "tecno-ciências" que permitem agregar valor a essas informações - ao agregarem valor aos novos produtos e processos a partir daí gerados -, passa então a ocupar um dos centros de disputa e de conflito no jogo de forças políticas e econômicas internacionais. Tal controle pode ser exercido tanto com o domínio do acesso aos recursos da biodiversidade, quanto por intermédio de instrumentos de proteção de direitos à propriedade intelectual, seja sobre as modernas biotecnologias, seja sobre os conhecimentos tradicionais de populações locais. Partindo dessas considerações, este artigo explora dois conjuntos de argumentos:

1) o de que a questão da biodiversidade deixa hoje de ser uma questão apenas ecológica, ou científico-tecnológica, para assumir também uma dimensão geopolítica;

2) o de que a "informacionalização" e a privatização da vida constituem duas facetas desse mesmo processo. 


\section{DA BIODIVERSIDADE À BIOTECNOLOGIA}

A questão da biodiversidade desponta dentre os temas ambientais planetários nos anos 80, juntamente com outras questões ambientais de alcance transfronteira, tais como a destruição da camada de ozônio, a mudança climática global associada ao efeito estufa, a poluição dos ambientes marítimos e a devastação das florestas ${ }^{1}$.

O conceito de biodiversidade inclui todos os produtos da evolução orgânica, ou seja, toda a vida biológica no planeta, em seus diferentes níveis - de gens até espécies e ecossistemas completos -, bem como sua capacidade de reprodução. Corresponde à "variabilidade viva", ao próprio grau de complexidade da vida, abrangendo a diversidade entre e no âmbito das espécies e de seus hábitats ${ }^{2}$.

A diversidade da vida é elemento essencial para o equilíbrio ambiental planetário, capacitando os ecossistemas a reagirem melhor às alterações sobre o meio ambiente causadas por fatores naturais e sociais, considerando que, sob a perspectiva ecológica, quanto maior a simplificação de um ecossistema, maior a sua fragilidade. A biodiversidade oferece também condições para que a própria humanidade adapte-se às mudanças operadas em seus meios físico e social e disponha de recursos que atendam a suas novas demandas e necessidades. Historicamente, as áreas de aproveitamento de recursos genéticos e biológicos têm sido inúmeras, destacando-se a alimentação, a agricultura e a medicina, dentre outras aplicações.

Em linhas gerais, duas grandes motivações contribuíram para a emergência recente da problemática da perda de biodiversidade na cena internacional e para determinar o seu caráter estratégico. Uma delas relaciona-se ao aumento da percepção, pelos cientistas e por crescentes segmentos da sociedade em geral, a respeito da urgência e da importância de se tomarem medidas de maior alcance visando a resguardar a existência das diferentes formas de vida na Terra.
A outra motivação, e talvez a mais fundamental, deve ser compreendida no contexto da passagem de um paradigma tecno-econômico intensivo em recursos naturais para um outro baseado em informação e no uso crescente de ciência e tecnologia no processo produtivo. Nesse contexto, a motivação determinante para o recente alarde em torno da questão da biodiversidade vem sendo a possibilidade, através do avanço da fronteira científico-tecnológica, de manipulação da vida ao nível genético, potencializando largamente seus usos e aplicações e ampliando o interesse de importantes segmentos econômicos e industriais na biodiversidade como capital natural de realização futura.

Dessa perspectiva, é principalmente como matéria-prima das biotecnologias avançadas que a biodiversidade assume hoje um caráter estratégico, valorizando-se nem tanto a vida em si, mas a informação genética nela contida. A biodiversidade investe-se assim de um duplo significado: enquanto elemento essencial de suporte à vida e enquanto reserva de valor futuro.

\section{A "INFORMACIONALIZAÇÃO" DA VIDA}

De modo geral, o conceito de biotecnologia pode incluir "qualquer técnica que utilize organismos vivos (ou partes de organismos), com algum dos seguintes objetivos: produção ou modificação de produtos; aperfeiçoamento de plantas ou animais e descoberta de microrganismos para usos específicos"3. No início da década de 70, a partir do desenvolvimento da técnica do $\mathrm{ADN}^{*}$ recombinante, permitindo a transferência de material genético entre organismos vivos através de meios bioquímicos, passaram a existir dois conceitos de biotecnologia: a biotecnologia tradicional e a biotecnologia moderna. Esta última está associada à possibilidade de obtenção de produtos e substâncias através das novas técnicas genéticas, e não só do cruzamento de espécies já existentes na natureza.

\footnotetext{
* O ADN, ácido desoxirribonucleico, ou DNA em inglês, é a substância responsável pela informação hereditária contida nos gens; ou seja, é o mensageiro molecular da herança, onde estão quimicamente inscritas as informações genéticas dos seres vivos.
}

Há cada vez maiores indícios de que boa parte das doenças possuem forte componente genético. Os avanços científicos nesses campos motivam grandes esperanças de que possam contribuir para prevenir ou combater doenças e disfunções até então causadoras de grandes males à humanidade e para multiplicar a oferta de alimentos de modo geral, do mesmo modo que prometem elevados ganhos econômicos com os novos produtos daí gerados.

A partir da convergência das ciências da biologia molecular, química e genética, abre-se a possibilidade de não só desvendar os mistérios da herança genética, como também de manipulá-la, o que faz com que o século XXI seja desde já considerado a era do gen ou do paradigma biotecnocientífico ${ }^{4}$.

O Projeto Genoma Humano, iniciado em 1990, envolvendo equipes científicas de vários países, com o objetivo de mapear e analisar todo o código genético humano, é o mais ambicioso nesse sentido. Só para se ter uma idéia dos interesses aí envolvidos, o Projeto Genoma custou, até agora, mais de 2 bilhões de libras, prometendo gerar, ao final da primeira década do próximo século, mais de 60 bilhões de dólares em vendas de medicamentos, o que representa metade de todas as vendas da indústria farmacêutica em 1992.

Em 1991, porém, quando os Institutos Nacionais de Saúde dos Estados Unidos registraram a patente de mais de 300 gens com funções ainda desconhecidas da ciência, as reações negativas a essa medida, em outros países, prenunciavam um verdadeiro conflito internacional sobre direitos comerciais sobre o ADN humano, ameaçando todo o esforço de colaboração científica internacional nessa. E, dada a complexidade e os elevados custos hoje envolvidos na atividade científica de ponta, apenas os grandes agentes econômicos possuem condições para desenvolvê-la, garantindo-Ihes assim o direito de apropriação de seus resultados. 
Esse avanço da fronteira científicotecnológica tem, portanto, implicações de toda ordem e, como assinalado por Tom Wilkie ${ }^{5}$, referindo-se ao Projeto Genoma, "a primeira questão a considerar é a do manejo desse conhecimento: quem tem direito de possuir informação sobre o ADN humano e quem deve ter acesso a ela?".

\section{A PRIVATIZAÇÃO DA VIDA}

Conforme lembrado por Santos ${ }^{6}$, "a matéria viva pode ser submetida à propriedade corpórea, pública ou privada [por exemplo, através da propriedade sobre o resultado de uma colheita], e à propriedade intelectual.", sendo esta última exercida por um prazo determinado e de acordo com a legislação estabelecida em dado território, a qual obedece princípios gerais internacionalmente definidos. Desse modo, "patentes vêm sendo concedidas para 'inovações tecnológicas' relacionadas com o todo ou parte de seres vivos, sejam estes microrganismos, plantas ou animais (transformados pela engenharia genética ou não), assim como para genes ou parte destes"7, abrangendo produtos, seus usos e processos de obtenção.

Os direitos de propriedade intelectual sobre seres vivos ou material biológico dizem respeito à informação contida nos gens do organismo e não ao organismo em si, diferenciando-se da propriedade física ou corpórea de uma dada espécie de planta ou animal. Apesar dessa diferença, a propriedade intelectual sobre um ser vivo ou matéria biológica pode afetar o acesso ao mesmo (ou a alguma de suas partes), bem como o uso que dele se faz, já que possibilita ao pseudo-inventoro exercício de direitos de monopólio, ainda que temporário, sobre sua reprodução e comercialização, ou a cessão desse direito em troca da cobrança de royalties.

Em 1871, pela primeira vez outorgou-se uma patente para um organismo vivo uma levedura livre de germes patogênicos, aperfeiçoando o processo de fabricação da cerveja -, a Louis Pasteur, na França. Alguns consideram que o marco jurídico internacional da concessão de patentes para organismos vivos, excluindo o homem, ocorreu quando da decisão da Suprema Corte Norte-Americana, em 1980, estabelecendo a patenteabilidade de microrga- nismos engenheirados per se como 'fabricação ou composição da matéria" (no caso, o patenteamento da bactéria Pseudomonas, baseando-se no fato de que a bactéria patenteada fora produzida em laboratório, tendo como aplicação a degradação do óleo cru) ${ }^{8}$.

A partir daí, houve crescimento vertiginoso dos pedidos de patente na área de engenharia genética ao nível mundial, seguindo aliás uma tendência geral de endurecimento e padronização dos mecanismos de proteção de direitos sobre a propriedade intelectual. O recente acordo Trade Related Intellectual Property Rights (TRIPs), firmado no âmbito da Organização Mundial do Comércio (OMC), é altamente abrangente no que se refere ao reconhecimento de direitos de propriedade intelectual nas áreas biológica e biotecnológica.

Utilizam-se hoje diferentes formas de proteção legal à propriedade intelectual relativamente à matéria viva, tais como patentes de seqüências de DNA, patentes de microrganismos, patentes de cultivares e de animais transgênicos, além de proteção de cultivares e de direitos do meIhorista ${ }^{9}$.

Patentes de seqüências de DNA permitem o patenteamento de cada característica de um dado ser vivo de maneira independente, fazendo com que o mesmo possa ser objeto de diferentes patentes. Apesar das resistências ao patenteamento de seqüências gênicas do ser humano, já ganha espaço a possibilidade de patenteamento de gens humanos a partir de seu uso em pesquisas com fins terapêuticos.

Patentes de microrganismos, de origem animal ou vegetal, podem ser concedidas à sua seqüência de DNA ou ao microrganismo per se, geralmente - mas nem sempre - de modo associado a um processo de geração de um produto determinado.

Patentes de cultivares não são concedidas a características isoladas, mas à nova variedade viva como um todo, obedecendo a todos os requisitos da concessão de patentes de modo geral.

Essa tendência ao estabelecimento de mecanismos de proteção à propriedade intelectual sobre seres vivos ou seus componentes vem gerando, no entanto, fortes controvérsias.
Uma primeira dificuldade reside na diferenciação entre um ser vivo natural e um produto biotecnológico, ou entre uma descoberta e uma invenção, quando se trata de um produto genético novo. Existe toda uma linha argumentativa segundo a qual as pesquisas biológicas e da engenharia genética geram, na verdade, descobertas e não invenções, já que nada mais fazem do que recombinar materiais genéticos preexistentes, ou isolar substâncias que ocorrem na natureza.

Uma segunda dificuldade da aplicação das leis de propriedade intelectual nas áreas biológica e biotecnológica consiste no atendimento ao requisito de plena descrição do objeto da patente, em particular quando se trata da descrição de todo ou de parte de um ser vivo (este problema é menor em relação a processos e produtos biotecnológicos) ${ }^{\star}$. Fica assim comprometida a possibilidade de reprodução do invento.

Um terceiro aspecto problemático, associado ao anterior, refere-se ao cada vez mais freqüente desrespeito ao requisito de aplicação industrial quando da solicitação de uma patente em biotecnologia, o que pode levar ao exercício de monopólio sobre materiais genéticos essenciais ao avanço da pesquisa e do conhecimento científico nessa área. Este problema tem sido recorrente no caso da solicitação de patenteamento de seqüências gênicas.

O escopo e a delimitação do objeto da patente são também um ponto controvertido nesses casos, por exemplo quanto à definição de que partes da estrutura física do gen devem ser patenteadas e sobre qual a abrangência da patente concedida (um mesmo processo biotecnológico poder gerar diferentes produtos, os quais podem ser, por sua vez, incorporados em outros tantos produtos).

\footnotetext{
* O Tratado de Budapeste (1977) procurou solucionar essa questão, pelo menos no que se refere aos microrganismos, estabelecendo um sistema internacional de depósitos de microrganismos, sob administração da OMPI. Não se cumpre, no entanto, com o requisito da descrição do invento; e ainda que o acesso a esses microrganismos seja restrito a fins de pesquisa, permanece o problema da segurança biológica.
} 
Além dessas questões "técnicas", a concessão de patentes nas áreas biológica e biotecnológica envolve outros aspectos de ordem moral, política e econômica, mobilizando diferentes grupos de interesse e levantando distintos pontos de vista.

Dado o caráter cada vez mais estratégico que assumem as novas biotecnologias, o fluxo internacional de informações e conhecimentos nessa área tende a estar, na opinião de especialistas, sob o controle político dos países de maior desenvolvimento científico-tecnológico, ocorrendo de modo desfavorável aos países em desenvolvimento ${ }^{10}$.

\section{CONSIDERAÇÕES FINAIS}

A exploração e a manipulação da natureza e de seus recursos, de início como simples matéria-prima utilizada na construção de uma base material para as sociedades industrializadas, vem também hoje servindo como fonte para as experimentações da ciência e tecnologia avançadas, dando origem à fabricação de produtos de alta sofisticação e de elevado valor agregado no mercado mundial, como assim sintetizado por Becker ${ }^{11}$ :

"O novo modo de produzir redefine a natureza e as relações sociedade-natureza. Por um lado, tende a se independentizar da base de recursos naturais utilizando menor volume de matériasprimas e de energia, mas, por outro, valoriza os elementos da natureza em um

\section{From biodiversity to biotechnology: a new information frontier}

\begin{abstract}
This article analyses the recent emergence of biodiversity issue in the context of the decline of a techno-economical paradigme intensive in the use of fuel energy and natural resources and the emergence of a techno-economical paradigme based in the use of information, science and technology in the productive system. In such a context it is through advanced biotechnologies that biodiversity has its value added in the globalized market, which does not valorize living organisms, but the information they contain.
\end{abstract}

\section{Keywords}

Biodiversity; Information; Science; Tecnhology; Biotechnology. outro patamar mediante o uso de novas tecnologias, sobretudo a biodiversidade - fonte de informação crucial para a biotecnologia - e a água, como possível matriz energética. Em outras palavras, valoriza a natureza como capital de realização atual ou futura."

Considerando o fato de que, como parte do atual cenário globalizado, acentua-se a tendência à apropriação privada de informações e de conhecimentos, mediante instrumentos legais cada vez mais rigorosos de proteção à propriedade intelectual, verifica-se que a natureza - e pode-se dizer a própria vida - é assim "virtualizada" em fragmentos microscópicos patenteáveis, tornando-se passível de privatização pelos grandes agentes econômicos.

Não é, portanto, a diversidade da natureza, ou da vida em si, o que vem sendo recentemente revalorizado. São as partículas genéticas, ou a informação nelas contida, o que tem valor estratégico para as biotecnologias avançadas. Através do mapeamento da informação codificada em gens e das novas tecnologias de clonagem e engenharia genética, possibilitam-se o desenvolvimento e a fabricação de produtos independentemente de seu território de origem.

Não se pode negar a contribuição que o desenvolvimento das modernas biotecnologias representam para a humanidade. No entanto, a apropriação privada (ainda que indireta) de recursos genéticos, promovida pela proteção patentária, pode contribuir para restringir o acesso aos recursos biogenéticos e, conseqüentemente, aos benefícios advindos de seu uso; bem como para diminuir o fluxo e o intercâmbio de material genético, podendo afetar áreas estratégicas, como a de medicamentos e a de segurança alimentar, particularmente quando se trata do patenteamento de plantas.

É preciso atentar para os possíveis, mas ainda imprevisíveis, impactos desses recentes desenvolvimentos científico-tecnológicos sobre o meio ambiente e a saúde humana e, particularmente, para as implicações éticas e políticas da redução da vida e de seus componentes a meras seqüências de informação passíveis de apropriação por agentes privados.

\section{REFERÊNCIAS BIBLIOGRÁFICAS}

1. ALBAGLI, Sarita. Dimensão geopolítica da biodiversidade. Rio de Janeiro: UFRJ/Programa de Pós-Graduação em Geografia, 1997 (tese de doutorado).

2. WILSON, Edward O. Biodiversity. Washigton: National Academy Press, 1988.

3. RAMALHO, Yolanda M. Melo. Et alii. Biotecnologia: cenário internacional e perspectivas para o Brasil. Rio de Janeiro:BNDES/ DEEST/AP, 1990. 204 p.

4. SCHRAMM, Fermin R. Paradigma biotecnocientífico e paradigma bioético. In: ODA, Leila M. (ed.) Biosafety of transgenic organisms in human health products. Rio de Janeiro: FIOCRUZ, 1996.

5. WILKIE, Tom. Projeto Genoma Humano: um conhecimento perigoso. Rio de Janeiro: Jorge Zahar Editora, 1994.

6. SANTOS, Márcio de M. Direitos de propriedade intelectual na área biológica: alguns pontos a serem considerados na preparação de legislações nacionais. Workshop "Biodiversidade: Perspectivas e Oportunidades Tecnológicas". Campinas, 29 de abril a 01 de maio de 1996.

7. Idem.

8. CRUZ, Murillo F. A norma do novo. Fundamentos do sistema de patentes na modernidade. Filosofia, História e Semiótica. Rio de Janeiro: M.F.C., 1996

9. VARELLA, M.D. Propriedade intelectual de setores emergentes: biotecnologia, fármacos e informática: de acordo com a Lei no. 9.279, de 14-5-1996. São Paulo: Atlas, 1996.

10. BARBOSA, Denis \& ARRUDA, Mauro F.M Sobre a propriedade intelectual. Campinas: UNICAMP, 1990 (Projeto "Desenvolvimento Tecnológico da Indústria e a Constituição de um Sistema Nacional de Inovação no Brasil").

11. BECKER, Bertha K. Novos rumos da política regional: por um desenvolvimento sustentável da fronteira amazônica In: BECKER, Bertha K. \& MIRANDA, Mariana (orgs.) $A$ geografia política do desenvolvimento sustentável. Rio de Janeiro: Editora UFRJ, 1997.

Artigo aceito para publicação em 27-4-98.

\section{Sarita Albagli}

Socióloga. D.Sc. em geografia. Pesquisadora do CNPq/IBICT e professora do Programa de Pós-Graduação em Ciência da Informação (Convênio CNPq/IBICT - UFRJ/ECO).

E-mail: albagli@omega.Incc.br 